\title{
Desconcentração polarizada da indústria em Goiás
}

\author{
Sergio Duarte de Castro \\ Pontifícia Universidade Católica de Goiás - Goiânia - GO - Brasil \\ ORCID: http://orcid.org/0000-0003-3951-6955 \\ Daniel Diniz Dias Batista \\ Pontifícia Universidade Católica de Goiás - Goiânia - GO - Brasil \\ ORCID: https://orcid.org/0000-0002-5705-7118
}

\section{Resumo}

Este artigo investiga o movimento de desconcentração da indústria de Goiás em direção ao interior, onde tende a permanecer concentrada em alguns novos centros, com uma dinâmica polarizada. Os novos polos industriais possuem diferentes estruturas produtivas, com distintos efeitos de polarização, graus de territorialização e capacidade de impulsionar o desenvolvimento local e regional. Propõe-se uma tipologia que ressalta essas principais diferenças, classificando-os em industriais urbanos, agroindustriais, de base mineral e mistos. Trata-se de uma contribuição original, muito útil para se pensar o processo de desconcentração industrial, especialmente nas regiões menos desenvolvidas. A construção da tipologia considerou diferentes dimensões dos polos, tais como tipo de aglomeração, fatores locacionais predominantes, grau de territorialização, integração com serviços modernos, links tecnológicos, porte e papel na rede urbana. Foram construídos indicadores para cada dimensão, utilizando-se, principalmente, dados da RAIS e do comércio vias internas da Secretaria da Fazenda, dando indicações para políticas industriais em nível subregional. Os principais polos industriais do estado foram analisados e classificados de acordo com a tipologia proposta: Goiânia e Anápolis como polos industriais urbanos; Rio Verde e Itumbiara como polos agroindustriais; Niquelândia como polo mineral; e Catalão como polo misto. Destacou-se o papel dos polos agroindustriais que, em decorrência de sua integração com a agropecuária local, criam circuitos virtuosos que tendem a se difundir por seu entorno. As novas tecnologias no campo da biotecnologia e na química verde possibilitam o avanço desses polos em direção a segmentos mais intensivos em conhecimento e valor.

Palavras-chave: Desconcentração industrial. Polos. Fatores locacionais. Goiás.

\section{Abstract}

\section{Polarized industry decentralisation in Goias}

This article investigates the movement of deconcentration of the Goiás's industry towards the interior, where it tends to remain concentrated in some new centers, with a polarized dynamics. The new industrial poles have different productive structures, with different polarization effects, degrees of territorialization and the ability to boost local and regional development. The article offers a typology that highlights these differences, classifying them into urban, agro-industrial, mineral-based and mixed industrials. This is an original 
contribution, very useful for thinking about the industrial deconcentration process, especially in less developed regions. The construction of the typology considers different dimensions of the centers, such as: type of agglomeration, predominant locational factors, degree of territorialization, integration with modern services, technological links, size and role in the urban network. Indicators were built for each dimension, using mainly data from RAIS and Finance Secretariat, giving indications for industrial policies at the sub-regional level. The main industrial Goiás's poles were analyzed and classified according to the proposed typology: Goiânia and Anápolis as urban industrial poles; Rio Verde and Itumbiara as agro-industrial poles; Niquelândia as a mineral pole; and Catalan as a mixed pole. The role of agro-industrial poles was highlighted, once, as a result of their integration with local agriculture, create virtuous circuits that tend to spread around their surroundings. New technologies in the field of biotechnology and green chemistry allows advancement of these poles towards segments more knowledge and value intensive.

Keywords: Industrial decentralisation. Poles. Locational factors. Goias.

Resumen

\section{Desconcentración polarizada de la industria en Goiás}

Este artículo investiga el movimiento de desconcentración de la industria de Goiás hacia el interior, donde tiende a permanecer concentrada en algunos nuevos centros emergentes, con una dinámica polarizada. Los nuevos polos industriales poseen diferentes estructuras productivas, con distintos efectos de polarización, grados de territorialización y capacidad de impulsar el desarrollo local y regional. Se propone una tipología que resalta esas principales diferencias, clasificando los polos en industriales urbanos, agroindustriales, de base mineral y mixtos. Es un aporte original, muy útil para reflexionar sobre el proceso de desconcentración industrial en el país, especialmente en las regiones menos desarrolladas. La construcción de la tipología consideró diferentes dimensiones de los polos, tales como tipo de aglomeración, factores locacionales predominantes, grado de territorialización, integración con servicios modernos, enlaces tecnológicos y porte y papel en la red urbana. Se construyeron indicadores para cada una de esas dimensiones, utilizando, principalmente, datos de la RAIS y del comercio vías internas de la Secretaría de Hacienda, dando indicaciones a políticas industriales a nivel subregional. Los principales polos industriales del estado fueron analizados y clasificados según la tipología propuesta: Goiânia y Anápolis como industriales urbanos; Rio Verde e Itumbiara como agroindustriales; Niquelândia como polo mineral; y Catalão como polo mixto. Se destacó el papel de los polos agroindustriales que, como resultado de su integración con la agricultura local, crean circuitos virtuosos que tienden a extenderse por su entorno. Las nuevas tecnologías en el campo de la biotecnología y la química verde permiten avanzar en estos ejes hacia segmentos más intensivos en conocimiento y valor.

Palabras-clave: Desconcentración industrial. Polos. Factores locales. Goiás

\section{Introdução}

Goiás é um estado de industrialização recente. A atividade industrial só passou a ter um papel de liderança no crescimento de sua economia a partir de meados dos anos 1970. As primeiras indústrias se estabeleceram no sul do estado, juntamente com a chegada dos trilhos da ferrovia Mogiana na região no início do século XX. A extensão da ferrovia até Anápolis em meados dos anos 1930, juntamente com a construção da nova capital, Goiânia, deslocou o crescimento industrial para o centro do estado. Esse processo se consolidou nos anos $1960 \mathrm{com}$ a transferência da capital federal para o Planalto Central e os vultosos 
investimentos em infraestrutura na região, sobretudo rodoviária, que acompanharam esse movimento. A concentração industrial em Goiânia e Anápolis atingiu seu auge em 1970, no bojo de um intenso processo de urbanização.

O peso da participação da indústria na produção do estado, entretanto, ainda permanecia muito limitado no início dos anos 1970. O primeiro salto significativo da produção industrial em Goiás se deu entre meados das décadas de 70 e 80. Esse processo de crescimento foi acompanhado também por um movimento de desconcentração industrial, que avançou em duas direções. Uma no sentido de novos polos industriais emergentes no interior do estado, e outro em direção ao entorno da capital, acompanhando a formação da região metropolitana de Goiânia. O surgimento de novos polos industriais no interior foi um desdobramento do avanço da fronteira agrícola e mineral para o Centro-Oeste, impulsionado pelos investimentos do II PND, que aprofundaram o movimento de integração logística e expansão geral da infraestrutura da região que vinha ocorrendo desde a construção de Brasília e o Plano de Metas.

Num primeiro momento, entre 1975 e 1985, desenvolveram-se principalmente polos industriais de base mineral em Catalão e na região norte de Goiás, esse último nucleado pelo município de Niquelândia. Paralelamente ocorria uma forte modernização agrícola, no bojo da qual emergia uma lenta agro industrialização polarizada pelos municípios de Rio Verde, no sudoeste, e Itumbiara, no sul. A partir de meados dos anos 1990 verificou-se um salto nesse processo, com a configuração de importantes complexos agroindustriais naqueles espaços.

Os polos industriais que emergiram nesse movimento possuem distintas estruturas e dinâmicas, diferentes graus de "territorialização" e capacidades de comando do território, bem como de impulsionar o crescimento no seu entorno. 0 objetivo do presente artigo é analisar essas diferenças, e propor uma tipologia dos polos industriais do estado a partir das mesmas.

O artigo está organizado em quatro seções, além das considerações finais. A primeira é esta introdução. Na segunda, faz-se uma sumária revisão bibliográfica da discussão em torno da temática das aglomerações produtivas, procurando situar a abordagem teórica utilizada neste trabalho. Na terceira, discute-se a concentração e desconcentração da indústria em Goiás, situando-a no quadro nacional. Na quarta se apresenta a metodologia e se formula a tipologia, bem como são analisadas as características dos principais polos do estado e classificados de acordo com a mesma. Por fim, as principais conclusões do trabalho são recuperadas nas considerações finais.

\section{Aglomerações e Crescimento Polarizado}

A distribuição desigual das atividades econômicas no espaço e sua tendência a se aglomerar são duas temáticas fundadoras das teorias de desenvolvimento regional. Não se pretende nessa seção fazer uma ampla recuperação da discussão em torno delas, mas tão somente apresentar e discutir sumariamente alguns conceitos e contribuições que, apesar de suas origens teóricas diversas, podem ser compatibilizadas e oferecer um arcabouço analítico consistente para tratar a problemática proposta neste artigo. 
A abordagem de Marshall sobre as externalidades espacialmente localizadas é a contribuição seminal sobre o tema e o ponto de interseção entre as várias teorias que o tratam. Marshall (1985) mostrou que os mesmos investimentos que geram economias de escala internos às firmas produzem efeitos não esperados sobre o seu entorno, que ele denomina de economias externas ou externalidades. São economias externas às firmas, mas internas ao território, gerando vantagens econômicas que induzem à aglomeração de firmas de uma mesma indústria. Assim, da mesma forma que os retornos crescentes de escala permitem explicar o crescimento desigual e a concentração econômica ao nível das indústrias, os efeitos cumulativos das externalidades ajudam a entender a concentração espacial das atividades econômicas e o crescimento desigual no espaço.

Contudo, nem todas as externalidades são positivas. Marshall (1985) revelou que a concentração espacial de empresas gera também "deseconomias de aglomeração", como pressões por elevação de salários, congestionamento e outros. Assim, ofereceu elementos teóricos para se pensar a tendência à concentração das atividades econômicas no espaço a partir do embate entre forças centrípetas e forças centrífugas.

Em sua grande síntese sobre a economia regional nos anos 1950, Isard (1956) distinguiu dois tipos de economias de aglomeração: economias de localização e economias de urbanização. As primeiras seriam as já referidas economias externas de tipo marshaliano, que podem ser entendidas como economias de especialização, na medida em que explicam as vantagens da aglomeração espacial de firmas de uma mesma indústria. Já as últimas seriam vantagens econômicas geradas pelas diversas atividades aglomeradas no ambiente urbano, como a disponibilidade de serviços variados, de infraestrutura, de mercado consumidor, bem como a ampla circulação de informações.

O conceito de economias urbanas foi enriquecido com as contribuições de James Jacobs (1969), com uma abordagem sistêmica e com foco na inovação. A autora apontou o papel da diversidade na vitalidade da economia das cidades, inspirada na teoria dos sistemas adaptativos complexos. Para Jacobs (1969), cada nova atividade econômica na cena urbana amplia as possibilidades de interações imprevistas geradoras de inovações incidentais, aprofundando ainda mais a divisão do trabalho. Esse ambiente crescentemente diverso potencializa a "fertilização cruzada de ideias", sendo altamente propício à criatividade e a inovação. Assim, para a autora é a diversidade, e não a especialização, a fonte mais relevante de economias externas.

O primeiro autor a tratar do papel das economias de aglomeração no campo da economia regional foi Alfred Weber, em 1909, em sua teoria sobre a localização das atividades industriais. Apesar de partir de um modelo de base neoclássica, com o suposto de retornos constantes e tendo como variável explicativa central os custos de transporte, Weber inseriu os ganhos decorrentes da aglomeração como uma variável adicional nas decisões dos empreendedores na localização de suas unidades.

Particularmente útil para os fins desse artigo é a tipologia proposta por Weber (1929) para classificar as indústrias segundo seus fatores locacionais predominantes, partindo do peso dos custos de transporte para cada tipo. Um tipo seria constituído por indústrias "footloose", para as quais os custos de transporte 
seriam irrelevantes, não interferindo em suas decisões locacionais. Outro por indústrias "orientadas para o mercado", aquelas para as quais os custos de distribuição são mais elevados e que, por essa razão, tendem a se localizar próximas aos seus mercados consumidores. O terceiro tipo, na tipologia de Weber (1929), seria de indústrias "orientadas para os recursos", cujos custos mais importantes são os de transportar os insumos, conduzindo-as a se instalarem nas proximidades de suas fontes de matérias-primas. Essas últimas ficaram conhecidas na literatura como "indústrias weberianas", e são particularmente importantes para se entender os processos de desconcentração industrial em direção a economias periféricas.

Outra contribuição essencial para abordagem utilizada nesse artigo é a visão perrouxiana dos polos de desenvolvimento. O ponto de partida de Perroux (1961) é a constatação de que o desenvolvimento não se distribui homogeneamente no espaço, mas se dá por meio de um dinâmica polarizada, em um processo de crescimento desequilibrado dotado de mecanismos cumulativos de auto reforço das desigualdades. Essa dinâmica se processa através da relação entre polos relativamente ativos e polos relativamente passivos que, segundo Perroux, pode ser entendida a partir da interação entre três efeitos: efeitos de aglomeração, efeitos de junção e efeitos de difusão.

Os efeitos de aglomeração decorrem das economias de escala associadas à proximidade, de natureza marshalliana, e embutem a tendência a concentrar as atividades nos polos mais dinâmicos. Os feitos de junção decorrem da conectividade entre os polos, são os canais por meio dos quais os impulsos entre eles se propagam. Já os efeitos de difusão, referem-se aos tipos de impulsos que se difundem entre os polos, podendo ser "efeitos de onda [de desenvolvimento] ou efeitos de frenagem" (PERROUX, 1961, p.167).

Essa dupla natureza dos efeitos de difusão foi aprofundada por Myrdal (1968). Esse autor argumentava que os polos dinâmicos produzem, simultaneamente, efeitos progressivos (spread effects) e efeitos regressivos (backwash effects) sobre os menos dinâmicos. Assim, esses últimos, ao mesmo tempo em que contam com externalidades positivas em decorrência de proximidade com os primeiros - como mercados mais amplos para seus produtos, acesso a centros de capacitação e formação de recursos humanos e outros -, estão sujeitos a externalidades negativas, como a perda de mão de obra qualificada, e capitais atraídos pelos polos mais avançados, entre outros efeitos.

Hirschman (2008) contribuiu para o entendimento da dinâmica do desenvolvimento polarizado por meio de sua teoria do crescimento como uma cadeia de desequilíbrios. Mergulhando na análise dos encadeamentos industriais, o autor mostrou que cada investimento novo em um indústria desencadeia uma série de investimentos induzidos, gerando efeitos a partir de seus encadeamentos para trás (backward linkages) - i.e impulsos de demanda para todas as indústrias fornecedoras da cadeia produtiva envolvida - e efeitos para frente (forward linkages), induzindo o estabelecimento/ampliação de consumidores produtivos de seus produtos. Assim, quanto maior for a intensidade dos encadeamentos produtivos de cada indústria, maior seu potencial de gerar efeitos multiplicadores. $E$, ainda, quanto mais denso for o conjunto de encadeamentos em cada economia, maior tende a ser seu potencial de crescimento industrial. 
As teorias da dinâmica do crescimento polarizado de Perroux, Myrdal e Hirschman foram concebidas no contexto que imperava após a segunda grande guerra. Naquele momento, o padrão fordista de produção, que vinha se desenvolvendo desde o início do século nos EUA, difundia-se entre os países desenvolvidos e alguns países de industrialização recente na periferia. A estabilidade do padrão tecnológico no período, que se encontrava em plena maturidade e com requisitos de difusão relativamente pouco complexos, levou a uma atenção limitada da teoria aos encadeamentos tecnológicos e à inovação, mantendo o foco nas interações produtivas, apesar da reconhecida influência do pensamento schumpeteriano sobre seus autores.

As contribuições de base evolucionista-neoshumpeteriana ao debate regional oferecem elementos para superar essa lacuna na análise dinâmica do crescimento polarizado. Na concepção evolucionista as decisões dos atores são baseadas em rotinas, e a inovação é a componente chave da concorrência. Ressalta-se que a inovação não é um ato isolado, mas um processo de aprendizado não-linear, cumulativo, espacial e historicamente contextualizado e institucionalmente determinado (CASTRO, et al 2017)

Além de envolver conhecimentos codificáveis, a capacidade de inovar depende simultaneamente de conhecimentos tácitos e específicos, não codificáveis e de difícil transferência. São conhecimentos que se acumulam nos indivíduos, nas firmas e outras instituições, bem como nos territórios. Por isso o aprendizado é fundamentalmente interativo e dependente do ambiente (LUNDVALL, 1992).

Essa é a essência do conceito mais difundido dessa corrente, o de Sistemas Nacionais de Inovação (SNI), que ressalta que a capacidade e o desempenho inovativo dos países são altamente dependentes de seu contexto sociopolíticoinstitucional, temporalmente e espacialmente situado. A literatura evolucionista se aproximou do debate sobre a questão regional dando ênfase à dimensão espacial do conceito de Sistemas de Inovação e destacando a importância da escala local, onde a produção e a inovação efetivamente acontecem. Formulou-se, nesse contexto, os conceitos de "sistemas regionais de inovação" (SAXENIAN, 1994) e de "sistemas locais de inovação" (CASSIOLATO et al, 2017), focados nas especificidades da proximidade nessa escala, bem como do ambiente cultural e institucional localizado para o aprendizado interativo, especialmente no que se refere ao intercâmbio de conhecimentos tácitos. No Brasil foi construído o conceito de Arranjos Produtivos Locais (APLs), um avanço teórico a partir da articulação entre a tradição neoschumpeteriana dos sistemas de inovação e o pensamento estruturalista latino-americano, com ampla difusão no meio acadêmico e no de formulação de políticas públicas de desenvolvimento no país (LASTRES e CASSIOLATO, 2017).

Generalizou-se, no início dos anos 2000, uma leitura reducionista das contribuições que destacavam o papel do local no desenvolvimento, o que Brandão (2018) chamou de "pensamento único localista". A base fundamentalmente sistêmica e multiescalar da noção de "sistemas de inovação", entretanto, desautorizam esse tipo de leitura, e asseguram sua compatibilidade com a abordagem da dinâmica do crescimento polarizado. 


\section{Concentração e desconcentração da indústria em Goiás}

Como mostrou Cano (1975), no final do século XIX e início do século XX o desenvolvimento e crise do complexo cafeeiro paulista reuniu no estado de São Paulo condições únicas para sediar a emergência da industrialização no Brasil. Esse impulso inicial desencadeou um poderoso círculo virtuoso de auto reforço de suas vantagens locacionais na atividade, assegurando sua supremacia na indústria do país.

Somente a partir de meados dos anos 1970 se verificou um movimento de reversão da concentração que, após uma interrupção entre meados das décadas de 80 e 90, estendeu-se até 2015 (Tabela 1).

Tabela 1- Participação das macrorregiões brasileiras e o estado de São Paulo no Valor da Transformação Industrial do Brasil (anos escolhidos)

\begin{tabular}{l|c|c|c|c}
\hline \multicolumn{1}{c|}{ Região } & $\begin{array}{c}\mathbf{1 9 7 3}(\%) \\
\text { Norte }\end{array}$ & $\begin{array}{c}1984 \\
(\%)\end{array}$ & $\begin{array}{c}1995 \\
(\%)\end{array}$ & $\begin{array}{c}\mathbf{2 0 1 5} \\
(\%)\end{array}$ \\
\hline Nordeste & 0,9 & 2,3 & 3,8 & 6,3 \\
\hline Sudeste & 5,9 & 10,3 & 7,4 & 10,5 \\
\hline São Paulo & 78,5 & 70,9 & 70,9 & 57,7 \\
\hline Sul & 58,3 & 49,6 & 51,8 & 33,9 \\
\hline Centro-Oeste & 13,8 & 15,2 & 16,4 & 19,8 \\
\hline
\end{tabular}

Fonte: PIA/IBGE

Os fatores que desencadearam esse movimento foram objeto de ampla análise nos anos 1980 e 1990, incluindo, entre outros: deseconomias de aglomeração na região metropolitana de São Paulo; infraestrutura, incentivos fiscais e investimentos diretos públicos; expansão das fronteiras agrícola e mineral (DINIZ, 1993; PACHECO, 1996).

O II Plano Nacional de Desenvolvimento (PND) teve um papel destacado neste processo. Dê um lado, por complementar e avançar nos investimentos em infraestrutura que já vinham do Plano do Metas, dando suporte ao espraiamento da urbanização e aprofundando a conectividade inter-regional. De outro, porque suas iniciativas tinham como foco a produção de bens intermediários - siderurgia, metais não ferrosos, petroquímica, fertilizantes, cimento, papel e celulose -, bem como o suporte à modernização agrícola. Diferentemente da fase anterior", parte importante das indústrias dessa nova etapa são fundamentalmente "weberianas", isto é, dependem da proximidade com suas matérias-primas, cujas fontes estão dispersas no território nacional. Assim, suas vantagens locacionais favoreciam objetivamente a desconcentração (CASTRO e ARRIEL, 2016; CASTRO, 2017).

\footnotetext{
${ }^{1}$ Para a indústria de bens duráveis, carro chefe da expansão entre meados dos anos 1950 e de 1970, a proximidade com os grandes mercados urbanos de média e alta renda das metrópoles do Sudeste, juntamente com outras óbvias economias de aglomeração de São Paulo no período, era um fator locacional muito importante, o que ajuda a explicar o movimento de concentração nessa fase.
} 
Para o Centro-Oeste, notadamente para Goiás, os investimentos do II PND foram particularmente significativos na medida em que complementavam a implementação do "cruzeiro rodoviário" a partir de Brasília, o ambicioso projeto de Juscelino Kubitscheck de construção de eixos rodoviários radiais, longitudinais e transversais conectando a nova capital federal com o conjunto do território nacional. $O$ importante fluxo migratório e os elevados investimentos em infraestrutura que acompanharam a construção de Brasília aceleraram a urbanização e ampliaram sobremaneira a interligação do Centro-Oeste com o mercado nacional e os portos.

O II PND foi também singularmente relevante para a região por suas ações voltadas à modernização agropecuária do país, aspecto pouco tratado na literatura. Em sua estratégia para o setor agropecuário o projeto do II PND afirmava: "Trata-se, agora, de exigir muito mais do setor agropecuário. [...] Significa [...] efetivar a vocação do Brasil como supridor mundial de alimentos, matérias-primas agrícolas e produtos agrícolas industrializados" (BRASIL, 1974).

O Plano viabilizou um amplo leque de ações voltadas para o avanço da fronteira agrícola e a modernização da agropecuária, não apenas para ampliar a produção interna de alimentos e gerar demanda complementar para a indústria, mas, sobretudo, para melhorar a balança comercial por meio da exportação de produtos de base primária.

Já estava em curso, desde o final dos anos 1960, a chamada "Revolução Verde" no Brasil, de rápida transformação da agricultura com uso intensivo de mecanização, melhoramento genético e insumos químicos (fertilizantes e defensivos), concentrada nas áreas de agropecuária mais avançadas do centro sul. As terras planas e baratas do Centro-Oeste, altamente propícias à mecanização, com regime de chuvas estável, somados aos avanços na logística e na infraestrutura em geral, se apresentavam nos anos 1970 como o cenário perfeito para a expansão do novo padrão agropecuário (CASTRO e ARRIEL, 2016).

O II PND garantiu recursos para a pesquisa tecnológica da recém-criada EMBRAPA, contribuindo para solucionar os problemas de acidez dos solos do cerrado e o desenvolvimento de sementes próprias para a região. Além disso, assegurou crédito farto e barato e apoiou a transferência de produtores experientes do sul do país para Goiás e o Mato Grosso, por meio de programas como o PRODOESTE e o PRODECER ${ }^{2}$.

Tudo isso permitiu que, em menos de 15 anos, o Centro-Oeste passasse de uma pecuária extensiva e uma pequena agricultura tradicional, para a liderança da moderna produção de grãos no país. Na produção de soja, carro chefe da modernização e da industrialização da agricultura brasileira, a região saiu de uma produção de $540 \mathrm{mil} /$ ton, na safra de 1976/1977, o que representava apenas 4,4\% da produção nacional, para 6,6 milhões/ton em 1990/1991, 43,3\% da safra brasileira naquele ano. Um crescimento de 11,3 vezes em 14 anos, que levou o Centro-Oeste à posição de maior produtor de soja do país (PIA/CONAB, 2019).

\footnotetext{
${ }^{2}$ Respectivamente: Programa de desenvolvimento dos cerrados e Programa de cooperação nipobrasileira para o desenvolvimento dos cerrados.
} 
O desenvolvimento industrial de Goiás está estreitamente associado a essas transformações vivenciadas pela região Centro-Oeste a partir da construção de Brasília e das condições que viabilizaram a expansão das fronteiras agrícola e mineral. Até 1965 a indústria em Goiás representava menos de $2 \%$ do PIB estadual. Um conjunto de fatores, mais diretamente associados à edificação da nova capital e ao avanço da urbanização, resultou em uma primeira ampliação significativa dessa participação entre 1965 e 1975. A presença da atividade industrial no produto bruto saltou de 1,4\% para 4,3\% no período (Gráfico 1).

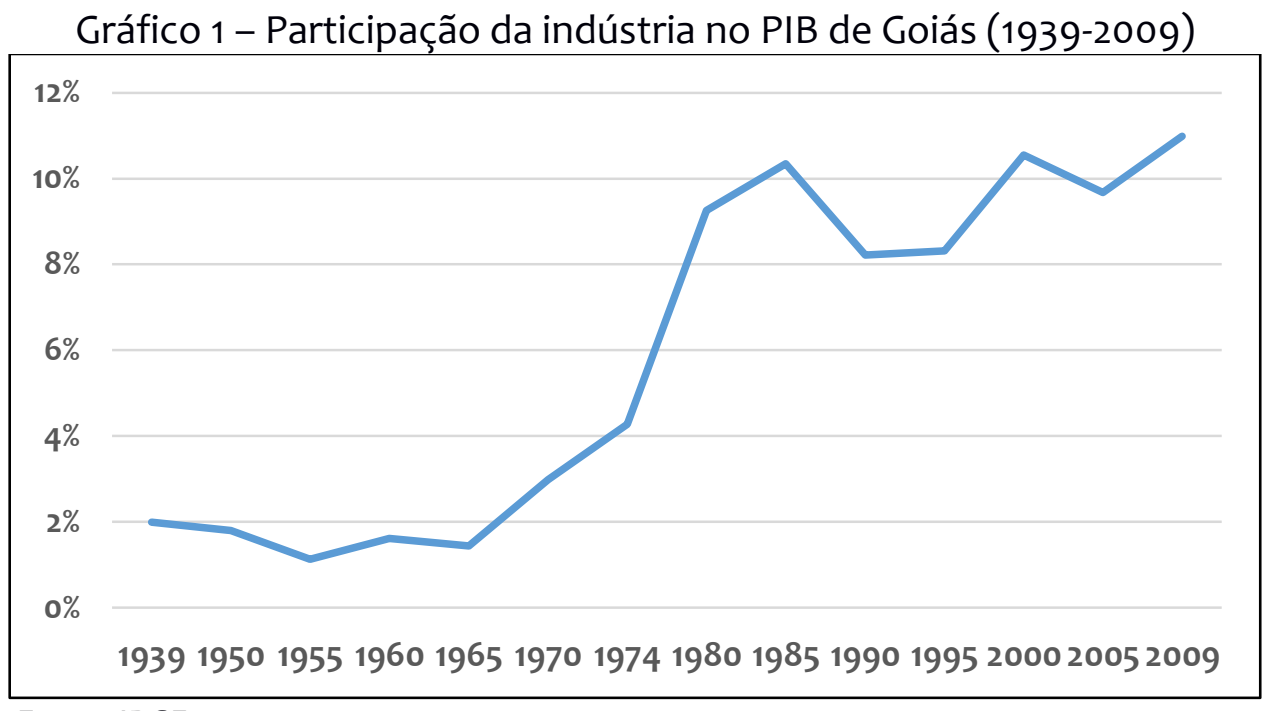

Fonte: IBGE

Entre esses fatores destacam-se: a demanda gerada pelas obras de edificação da nova capital e de infraestrutura; o salto de qualidade em termos de conexão rodoviária com o resto do país; a ampliação da infraestrutura urbana e do mercado consumidor de Brasília e Goiânia. Em 1950 apenas 21,7\% da população de Goiás vivia em cidades, em 1970 esse percentual já havia saltado para 45,9\%. As duas jovens capitais, Goiânia e Brasília, situadas a uma distância de apenas 200 km uma da outra, tornaram-se os dois polos de maior atração populacional relativa do país no período. Entre 1960 e 1970 a população de Brasília cresceu 14,4\% a.a. e a de Goiânia a 9,7\% a.a., taxas muito superiores à média das capitais brasileiras na década, que foi de $4,5 \%$ a.a. (IBGE).

Anápolis, localizada entre as duas capitais na BRo60, a 45 km de Goiânia e $150 \mathrm{~km}$ de Brasília, completava um eixo do qual emanavam fortes economias de aglomeração. O crescimento industrial de Goiás nessa fase se concentrou, sobretudo, em Goiânia e Anápolis. A participação conjunta dos dois municípios na população urbana do estado saltou de 13,8\% em 1960 para 40,9\% em 1970, ao mesmo tempo em que a soma de sua parcela no valor adicionado industrial (VAI) de Goiás passou de $39,2 \%$ para $55,5 \%$ (IBGE).

Um novo impulso ao avanço da industrialização se deu após 1975, no quadro da desconcentração industrial nacional e das transformações produzidas na agropecuária e na mineração. A participação da indústria no PIB deu um novo salto entre 1975 e 1995, passando de 4,3\% para 8,3\% (Gráfico 1). Nessa fase se iniciou uma etapa de desconcentração industrial no estado, seguindo basicamente duas direções. Uma no sentido de novos polos industriais emergentes no interior do 
estado e outra rumo ao entorno da capital, acompanhando a formação de sua região metropolitana.

A desconcentração industrial da capital em direção ao seu entorno imediato teve basicamente três razões: as deseconomias de aglomeração em Goiânia; a possibilidade de contar com as economias urbanas da capital; e a política de incentivos fiscais do governo estadual estimulando a desconcentração. Em 1970 Goiânia concentrava 90,9\% do VAl da RMG, em 1996 essa participação havia se reduzido para $85,0 \%$, caindo para $61,4 \%$ em 2010 (IBGE). A indústria se espraiou principalmente para oito municípios do entorno imediato da capital ${ }^{3}$.

A desconcentração em direção ao interior do estado também foi estimulada por incentivos fiscais. Contudo, ela se explica, principalmente, pelo desdobramento do deslocamento da fronteira agrícola e mineral para Goiás no âmbito da indústria (CASTRO e ARRIEL, 2016).

Emergiram, entre meados dos anos 1970 e início dos anos 2000, quatro novos polos industriais significativos no interior de Goiás. Dois eram polos de base mineral, que tiveram seu principal momento de crescimento entre 1975 e 1985. Um localizado em Catalão, no extremo sudeste de Goiás, e outro, no norte, no município de Niquelândia. A participação do VAl desses polos no VAl do estado passou de 1,4\%, em 1975, para 20,1\%, em 1985 (Gráfico 2).

Gráfico 2 - Participação dos principais polos industriais no VAl* de Goiás (19592010)

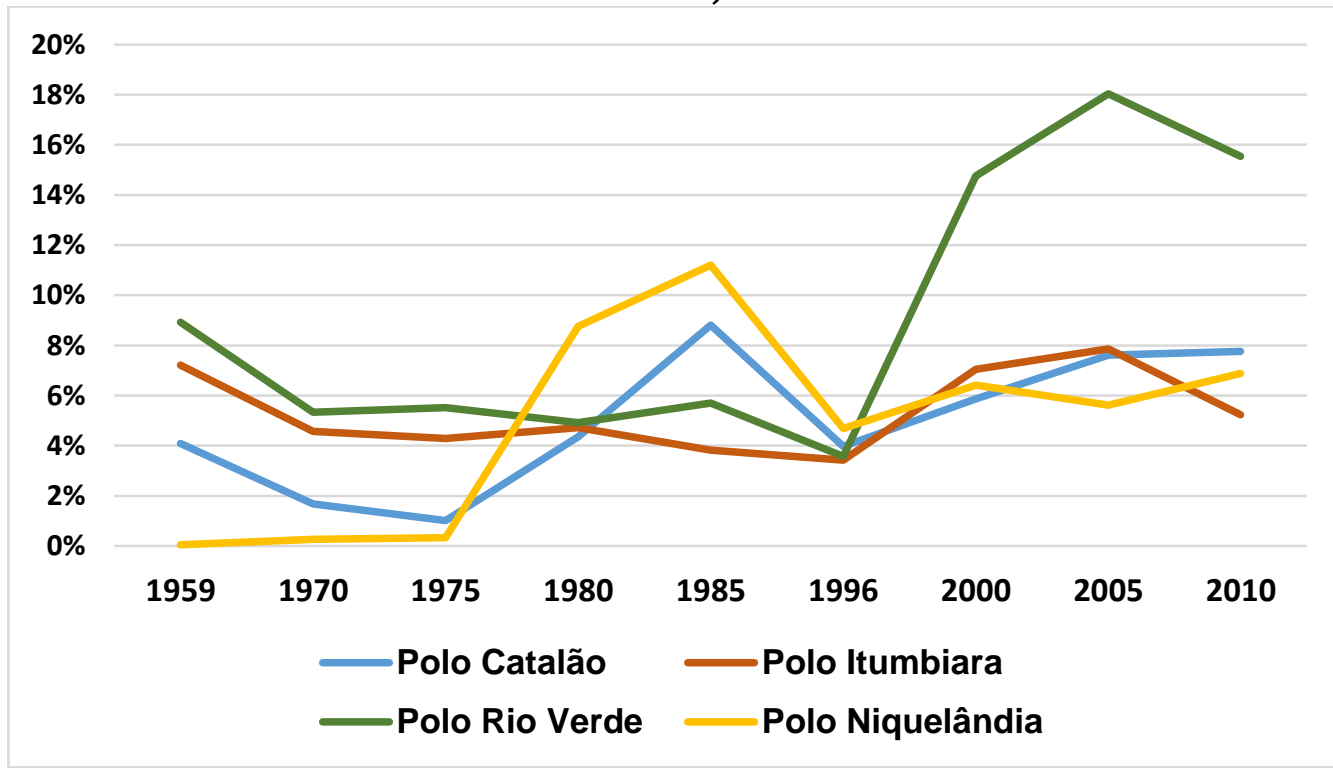

Fonte: IBGE

*Valor adicionado da indústria.

Nota: os dados de cada polo incluem os da cidade polo e dos municípios que se mais industrializaram em sua área de influência ${ }^{4}$.

\footnotetext{
${ }^{3}$ A Região Metropolitana de Goiânia (RMG) é integrada por 20 municípios. O polo industrial de Goiânia, definido nesse trabalho, refere-se apenas à própria capital e aos oito municípios que integram a RMG nos quais a indústria avançou. Esse conjunto correspondia a 98,1\% do VAI da RMG em 2010 (IBGE).
} 
Outros dois polos, esses de base agroindustrial, viveram um momento de intensa modernização agropecuária entre 1975 e 1995, com algum desenvolvimento industrial, que deslanchou efetivamente após essa última data. Trata-se de Rio Verde, no sudoeste do estado, e Itumbiara, que se situa no sul de Goiás, na fronteira com Minas Gerais. A participação desses novos polos, no VAl estadual passou de 7,0\%, em 1996, para 25,8\%, em 2005 (Gráfico 2).

O polo de Catalão, hoje um importante complexo minero-químico, resultou de incentivos e investimentos diretos do governo federal, a partir do Programa Nacional de Fertilizantes e Calcário Agrícola (PNFCA), que integrava o II PND. Em 1976-77 a empresa Mineração Catalão se instalou em Catalão e no município contíguo de Ouvidor para produção de ferro-nióbio e, em 1979, foi constituída uma empresa pública, a Goiasfértil ${ }^{5}$, para produção de concentrado fosfático, ambos com incentivos do PNFCA.

No Norte do estado, na região de Niquelândia, uma das maiores jazidas de níquel do mundo, já mapeada desde os anos 1940, só teve sua exploração viabilizada nos anos 1980, a partir do avanço da infraestrutura rodoviária e de energia no estado, como desdobramento do II PND. Esse polo, envolve apenas Niquelândia e o município vizinho Barro Alto, por onde se estende a jazida e a operação das grandes empresas. Outros dois importantes polos minerais emergiram no Norte do estado pelas mesmas razões. No maior deles, no município de Minaçu, a empresa SAMA S.A explora Amianto Crisotila, para a produção de fibrocimento, desde 1967. O segundo, de exploração de ouro e cobre, envolvendo principalmente os municípios de Crixas, Pilar de Goiás e Alto Horizonte, surgiu um pouco mais tarde, no final dos anos 1980. Esse artigo tratará apenas do polo de Niquelândia, cujas características são muito semelhantes aos demais polos minerais da região.

Rio Verde foi uma das prioridades do programa POLOCENTRO/II PND nos anos 1970, passando por um rápido processo de modernização agropecuária. Paralelamente ao avanço da agropecuária, que transformou a região em uma das maiores produtoras de soja do país, iniciou-se a agroindustrialização de grãos sob a liderança da Cooperativa Mista dos Produtores Rurais do Sudoeste Goiano (COMIGO). Contudo, o polo deu efetivamente um salto de qualidade em sua base industrial a partir de meados dos anos 1990, com a estruturação de um complexo industrial portuário em São Simão - que conectou a região à Hidrovia Tietê-Paraná -, e a implantação de uma unidade da Perdigão (BR Foods) em Rio Verde, configurando-se um grande complexo agroindustrial de grãos e carnes no sudoeste goiano. A região foi, também, um dos principais centros de atração de investimentos na expansão da indústria sucroalcooleira no estado na segunda metade de 2000. As atividades industriais se espraiaram no território, alcançando principalmente os municípios de Jataí, Mineiros, Quirinópolis, Santa Helena e São Simão. Entre 1996 e 2005, a participação do polo de Rio Verde, integrado por esse e os demais municípios referidos, passou de 3,5\% para 18,0\% (Gráfico 2).

Itumbiara, tal como Rio Verde, modernizou sua agropecuária grosso modo entre 1975 e 1995 e, em seguida, avançou na constituição de importantes complexos agroindustriais que se estruturaram no seu entorno. Os municípios próximos onde a 
industrialização avançou, integrando esse polo, foram Cachoeira Dourada, Morrinhos e Goiatuba Os segmentos principais foram o processamento de milho, lácteos, tomate e, um pouco mais tarde, o sucroalcooleiro. A participação do polo de Itumbiara, constituído por esse município e seu entorno mais industrializado, no VAl goiano passou de 4,3\% em 1975, para 7,9\% em 2005 (Gráfico 2).

\section{Tipologia dos polos industriais de Goiás}

Uma tipologia é uma classificação de qualquer conjunto em um determinado número de subconjuntos que agrupam seus integrantes em determinados tipos, a partir de suas propriedades comuns. É necessário ressaltar, entretanto, que a abordagem teórica utilizada nesse ensaio destaca, sobretudo, a natureza histórico específica da trajetória de cada território e suas estruturas. A tipologia proposta aqui é apenas um recurso metodológico útil para ressaltar características gerais representativas das estruturas de determinados tipos de polos, cujas trajetórias concretas são particulares e fortemente dependentes de suas histórias e contextos institucionais específicos. Os tipos não podem, portanto, ser interpretados como qualquer forma de padrão de desenvolvimento.

Tipologias têm sido amplamente utilizadas como recurso metodológico no campo da economia regional e urbana. São comuns tipologias de territórios, como as do IBGE (2017) e do Ministério da Integração Nacional (MACEDO e PORTO, 2018), tipologias de cidades e aglomerações urbanas (PINA; FREIRE e TURCZYN, 2020), assim como tipologias de clusters industriais e de APLs (STADUTO; PINELA e WILLERS, 2018). Entretanto, não se encontrou na literatura nenhuma tipologia de polos industriais urbanos, como as propostas nesse trabalho. Trata-se de uma contribuição original, muito útil para se pensar o processo de desconcentração industrial no país, especialmente nas regiões menos desenvolvidas.

Polos industriais urbanos são definidos aqui como aglomerações produtivas com dominância industrial, constituídas por uma cidade polo que concentra a maior parte do VAl e das economias urbanas do polo, e dos municípios em seu entorno que se industrializaram a partir do transbordamento do desenvolvimento daquela. É constituído por um ou vários APLs de diferentes naturezas.

Para organizar as características que servirão de base para a tipologia proposta, serão consideradas seis dimensões: o tipo de aglomeração; os fatores locacionais predominantes; o nível de territorialização; a integração com serviços modernos; os links tecnológicos; bem como o porte e o papel dos municípios polo na rede urbana do estado (Quadro 1). Os indicadores referentes à essas dimensões serão construídos com dados das cidades polos, uma vez que nessas se concentra a base dos impulsos dinâmicos para o polo e, a partir dele, para o restante do território ${ }^{6}$.

\footnotetext{
${ }^{6}$ É importante, num segundo momento, se avançar para uma análise da dinâmica interna de cada polo e de como essa se desdobra nos efeitos sobre o território em diferentes escalas. Essa etapa, entretanto, exigiria um tratamento no nível dos distintos APLs que convivem e interagem em cada polo, suas configurações produtivas e inovativas, formas de coordenação, processo de aprendizagem e construção de competências, fluxos de conhecimento e outros fatores considerados nessa dimensão sistêmica de análise.
} 
Quadro 1-Elementos para tipologia de polos industriais

\begin{tabular}{|l|l|c|}
\hline \multicolumn{1}{|c|}{ DIMENSÕES } & \multicolumn{1}{|c|}{ INDICADORES } & RESULTADOS \\
\hline Tipo de Aglomeração & $\begin{array}{l}\text { Índice de Diversificação Industrial (IDInd) } \\
\text { e Razão de Concentração }\end{array}$ & Especializado / Diversificado \\
\hline Fatores Locacionais & Tipo de Indústria Predomina & $\begin{array}{c}\text { Weberiano-Agro/Weberiano- } \\
\text { Minero/Outros }\end{array}$ \\
\hline Territorialização & Índice de Territorialização (IT) & Alto / Baixo \\
\hline $\begin{array}{l}\text { Integração com } \\
\text { Serviços Modernos }\end{array}$ & Índice de Diversificação dos SIC* (IDSic) & Alta/Média /Baixa \\
\hline Links Tecnológicos & Serviços C,T\&I & Alta/Média /Baixa \\
\hline $\begin{array}{l}\text { Porte e Hierarquia do } \\
\text { Município }\end{array}$ & População e Papel na Rede Urbana & $\begin{array}{c}\text { Pequeno / Médio / Grande e } \\
\text { Classificação Regic/IBGE }\end{array}$ \\
\hline
\end{tabular}

Fonte: Elaboração própria

*Serviços intensivos em conhecimento

A dimensão "tipo de aglomeração" refere-se à natureza das externalidades determinantes da aglomeração industrial do polo: se economias de especialização de base marshaliana ou economias de urbanização do tipo Jacobs. Os indicadores utilizados são o Índice de Diversificação Industrial (IDInd) e a Razão de Concentração $(C R)$ setorial. O Idind foi obtido por meio da relação entre o número de atividades industriais presentes no município e o número de atividades totais possíveis, de acordo com a classificação em nível de sub-classes da CNAE 2.0, utilizando os dados da RAIS para o ano de 2015.

A razão de concentração foi calculada com base na participação relativa dos dois maiores setores, agrupados a dois dígitos da CNAE, no faturamento da indústria de cada polo (CR2). Os dados de faturamento utilizados são da Secretaria da Fazenda de Goiás (SEFAZ-Go) e referem-se às vendas do setor industrial em nível municipal.

Para o quesito "fatores locacionais" foi utilizada a clássica tipologia de Weber (1929). Diferenciou-se as chamadas indústrias weberianas das demais e, em seguida, as weberianas de base agroindustrial das de base mineral.

Quanto à dimensão "territorialização", é preciso inicialmente dizer que o termo territorialização está sendo utilizado aqui no sentido estrito de enraizamento territorial da atividade industrial, ou do seu grau de interdependência produtiva local. Trata-se de averiguar a densidade dos vínculos intersetoriais locais ou linkages, no sentido atribuído por Hirschman (2008). O indicador desenvolvido para apreender essa dimensão, que estamos denominando de Índice de Territorialização (IT), é a medida da relação entre as compras que a indústria da cidade polo realiza na sua microrregião e o total de suas compras. Trata-se de uma proxi dos vínculos a montante das firmas industriais locais entre elas e com todo o tecido produtivo local e regional. Assim, quanto maior o IT maior a interdependência e, portanto, maiores serão os efeitos de encadeamento, bem como os impactos do desenvolvimento da cidade polo no seu entorno.

A dimensão "integração com serviços modernos" procura captar a interação indústria/serviços produtivos e o crescente papel dos últimos. Com as transformações produtivas e tecnológicas da nova fase da economia intensiva em conhecimento as empresas passam a operar cada vez mais em rede, seja por meio da articulação com empresas do mesmo segmento, seja através da subcontratação 
de atividades. A consequência é uma crescente terceirização das atividades da indústria, elevando a complementaridade entre a indústria e os serviços. Bens e serviços se combinam, relacionando-se de maneira cada vez mais sinergética para formar um produto que não é um bem industrial comum, nem um serviço convencional, mas sim, bens com vários serviços agregados no valor final (ARBACHE, 2015).

Neste quadro se amplia, especialmente, a demanda por serviços cada vez mais complexos e intensivos em conhecimento, o que a literatura internacional tem chamado de Knowledge Intensive Business Firms (Kibs) (BRENNER et al 2018; HERNÁNDEZ et al, 2016), traduzido por autores brasileiros como Serviços Intensivos em Conhecimento (SICS) (SOBREIRA; PADRÃO, 2019). Os SICS podem ser definidos como uma categoria de serviços altamente inovativos que, ao mesmo tempo, desempenham um papel destacado na inovação em outros setores (SOBREIRA; PADRÃO, 2019).

Dadas as evidências da crescente interpenetração indústria e serviços, podese esperar uma correlação significativa entre a diversidade dos SICs e a complexidade do tecido produtivo do território, em especial de seu setor industrial. Como indicador da diversidade dos SICs em cada polo se utilizará um Índice de Diversificação de SICS (IDSic), calculado a partir da relação entre o número de atividades SIC existentes no município e o número total de SICs existentes, classificados em sub-classes da CNE 2.0.

A dimensão referida aos "links tecnológicos" procura captar as interdependências nesse campo no conjunto do tecido produtivo local. Para tanto se utilizará como indicador a participação percentual do número de ocupados em serviços de ciência, tecnologia e inovação (ServCt\&l) do município no total dos ocupados nesse tipo de serviços no estado. Os ServCT\&l incluem ocupados em instituições de ensino, superior e pesquisa, bem como de formação técnica e tecnológica, além de parte dos SICs que estão mais diretamente envolvidos com o processo de geração e difusão de inovações.

A dimensão "porte e hierarquia do município" procura captar, de um lado, o peso de suas economias urbanas, que está diretamente associado ao tamanho da cidade e, de outro lado, o papel do polo na rede de cidades do estado. Papel esse que está relacionado à função desempenhada pelo centro urbano e sua capacidade de comando e gestão do território. Os indicadores utilizados são o número de habitantes e a classificação do município na Região de Influência das Cidades $2018^{7}$ (IBGE, 2019).

Tendo como referência as dimensões propostas pode-se dividir os polos industriais do estado em quatro grandes tipos: industriais urbanos; agroindustriais; de base mineral e mistos (Quadro 2).

\footnotetext{
${ }^{7}$ A classificação da REGIC 2018 levou em conta o papel de cada município na gestão política e econômica do território, a intensidade de seus relacionamentos com outros municípios e a dimensão da região de influência de cada centro. Os 5.564 municípios brasileiros vigentes em 2018 foram classificados em cinco grandes níveis que, por sua vez, se subdividem em dois ou três subníveis. Os grandes níveis são: Metrópole; Capital-Regional; Centro Sub-Regional; Centro de Zona; e Centro Local (IBGE, 2020).
} 
Quadro 2 - Tipologia de polos industriais

\begin{tabular}{|c|c|}
\hline Tipos & Características \\
\hline $\begin{array}{l}\text { Polos Industriais } \\
\text { Urbanos }\end{array}$ & $\begin{array}{l}\text { - } \quad \text { Diversificado, predomínio de economias urbanas; } \\
\text { - } \quad \text { localizado em cidades de maior porte e regiões metropolitanas; } \\
\text { - } \quad \text { baixa territorialização; } \\
\text { - } \quad \text { forte concentraçãa de serviços de C,T\&I }\end{array}$ \\
\hline Polos & - Especializado - economias de aglomeração weberianas/agro \\
\hline Agroindustriais & $\begin{array}{l}\text { - } \quad \text { especialização agropecuária em commodities “modernas” e } \\
\text { - } \quad \text { localizado em cidades de porte médio/pequeno fora das regiões } \\
\text { - } \text { metropolitas; } \\
\text { - } \quad \text { média integração com SICs } \\
\text { - média concentração de serviços de C,T\&I }\end{array}$ \\
\hline $\begin{array}{l}\text { Polos Base } \\
\text { Mineral }\end{array}$ & $\begin{array}{l}\text { - } \quad \text { Especializado, predomínio de economias de aglomeração } \\
\text { - } \quad \text { Esperianas/minerais; } \\
\text { - } \quad \text { localizado em cidades pequenas/médias fora das regiões metropolitas; } \\
\text { - } \quad \text { baixa territorialização } \\
\text { - } \quad \text { baixa integração com SICs } \\
\text { - } \quad \text { baixíssima presença de serviços de C,T\&I }\end{array}$ \\
\hline Polos Mistos & $\begin{array}{l}\text { - } \quad \text { Relativa concentração em agroindústria ou base mineral; } \\
\text { - } \quad \text { alguma diversificação decorrente de economias urbanas e de polarização } \\
\text { - } \quad \text { localizado em cidades médias fora de regiões metropolitanas e em eixos } \\
\text { - logísticos importantes; } \\
\text { - média/baixa integração com SICs } \\
\text { média concentração de serviços de C,T\&l }\end{array}$ \\
\hline
\end{tabular}

Fonte: elaboração própria.

Os polos industriais urbanos apresentam um tecido industrial mais diversificado, característico de aglomerações onde predominam externalidades de tipo Jacobs. Por esta razão tendem a se localizar em regiões metropolitanas e/ou cidades médias de maior porte, que possuem infraestruturas urbanas maiores e mais complexas. Essas infraestruturas, por sua vez, são decisivas para a ocorrência de uma concentração mais elevada de SICs. Apresentam uma maior participação de ServCT\&l em função do papel central que ocupam na rede urbana estadual, não estando associados, necessariamente, a um maior esforço inovador. Uma característica que merece particular atenção nesses polos é sua baixa territorialização. Um tecido industrial com baixa integração, produto da baixa presença de segmentos fornecedores de insumos industriais e de limitações de escala para desenvolvê-los e, portanto, com limitados backward linkages e forward linkages.

Os polos agroindustriais são especializados na grande agroindústria moderna e commodities agropecuárias associadas, localizados em geral em cidades de porte médio situadas fora de regiões metropolitas. Constituem um importante vetor de desconcentração industrial e apresentam elevada territorialização, uma vez que suas indústrias processam basicamente matérias primas locais e tendem a atrair segmentos complementares a montante como equipamentos, embalagens, 
empresas de genética e outras. Tendem a possuir uma rede de SICs média, relativamente robusta, em decorrência da demanda e integração com esses serviços, tanto por parte da agroindústria com da agropecuária moderna, em crescente processo de terceirização. Sua base de fornecimento se espraia pela região em seu entorno, de forma que o efeito multiplicador decorrente de sua territorialização estimula o crescimento de seu entorno. Essa característica reforça seu papel de gestão e comando do território e se expressa em uma média concentração de ServC,T\&I.

Os polos minerais, por sua vez, são fortemente especializados na extração e processamento inicial de matérias-primas minerais. Trata-se de uma atividade que possui elevada rigidez locacional, i.e., tem que se localizar necessariamente junto a suas fontes de matérias-primas. Tais polos situam-se, em geral, em cidades pequenas e médias, possuindo baixa dependência de economias urbanas para o seu desenvolvimento $^{8}$. Caracterizam-se por baixíssima territorialização, sendo verdadeiros enclaves nas regiões em que se estabelecem, com praticamente nenhuma interação com o tecido produtivo local e regional. Assim, apesar de movimentar grandes investimentos, dado que a atividade é intensiva em capital, seu impacto sobre o desenvolvimento do município e seu entorno é muito baixo, limitando-se praticamente ao efeito renda decorrente dos salários pagos aos trabalhadores locais, que se ocupam, em geral, das tarefas mais simples. A baixa diferenciação dos serviços como um todo, bem com a limitada presença de SICs e de ServCT\&I, são uma expressão dessas limitações.

Os polos mistos combinam caraterísticas dos demais. Trata-se de polos que possuem um certo grau de especialização em agroindústrias e/ou base mineral, mas que, em decorrência de seu porte, posição logística e políticas públicas, conseguem avançar na diversificação industrial e no desenvolvimento do setor de serviços. Possuem assim, níveis médios de desenvolvimento de SICs e ServC,T\&I.

Os dados calculados para os indicadores estão sintetizados no quadro 3. A partir deles passamos à uma breve análise de enquadramento de cada polo na tipologia proposta, organizada no quadro 4.

\footnotetext{
${ }^{8}$ As etapas de transformação mais avançadas dos produtos da mineração, com maior agregação de valor e inovação, dependem de economias de urbanização importantes e tendem a se localizar em cidades de maior porte em regiões desenvolvidas dentro ou fora do país. Na ausência de políticas industriais muito ativas os polos minerais em regiões pouco desenvolvidas permanecem limitados às atividades de extração e transformação inicial.
} 
Quadro 3 - Indicadores dos municípios polo (2015)

\begin{tabular}{|c|c|c|c|c|c|c|c|c|}
\hline Município & $\begin{array}{l}\text { Classificação } \\
\text { REGIC } 2007\end{array}$ & $\begin{array}{l}\operatorname{Pop}^{\mathrm{a}} \\
\text { (hab) }\end{array}$ & IDInd $^{\mathrm{b}}$ & $\underset{(\%)}{\mathrm{CR}^{\mathrm{C}}}$ & $\mathrm{IDS}^{\mathrm{d}}$ & $I T^{e}$ & $I_{D S I C}$ & $\begin{array}{c}\text { Serviços } \\
\text { CT\& } \mathrm{I}^{\mathrm{g}} \\
(\%)\end{array}$ \\
\hline Goiânia & Metrópole & 1.430 .697 & 0,72 & 60,2 & 0,78 & 0,23 & 0,76 & 51,1 \\
\hline Anápolis & $\begin{array}{l}\text { Sub-Centro } \\
\text { Regional A }\end{array}$ & 366.491 & 0,53 & 26,6 & 0,53 & 0,22 & 0,45 & 19,3 \\
\hline Rio Verde & $\begin{array}{l}\text { Sub-Centro } \\
\text { Regional A }\end{array}$ & 207.296 & 0,34 & 96,4 & 0,45 & 0,57 & 0,37 & 6,3 \\
\hline Itumbiara & $\begin{array}{l}\text { Sub-Centro } \\
\text { Regional A }\end{array}$ & 100.548 & 0,28 & 78,0 & 0,36 & 0,30 & 0,26 & 0,9 \\
\hline Catalão & $\begin{array}{c}\text { Centro de Zona } \\
\text { A }\end{array}$ & 98.737 & 0,25 & 86,2 & 0,38 & 0,31 & 0,28 & 1,0 \\
\hline Niquelândia & $\begin{array}{c}\text { Centro de Zona } \\
\text { B }\end{array}$ & 31.031 & 0,10 & 96,9 & 0,13 & 0,13 & 0,05 & 0,1 \\
\hline
\end{tabular}

Fonte: IBGE, Rais/TEM, SEFAZ/Go

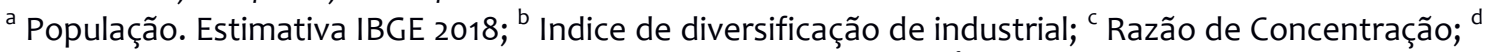
Indice de diversificação de serviços; ${ }^{e}$ Índice de Territorialização; ${ }^{f}$ Indice de diversificação de serviços intensivos em conhecimento; ${ }^{8}$ Serviços na área de ciência, tecnologia e inovação

Esses números, entretanto, expressam muito mais a amplitude da área de influência dos seus serviços, do que a presença de esforço inovativo das firmas que integram o polo. A indústria da capital, na verdade, é concentrada em setores de baixa e média baixa intensidade tecnológica. São setores dominados por fornecedores, com um esforço inovativo em geral limitado e que ocorre, essencialmente, por meio da aquisição de máquinas e equipamentos. A cidade possui um índice de diversificação industrial (IDInd) elevado, acompanhado, porém, de uma concentração relativamente alta da indústria. Isso significa que ela possui firmas em um amplo leque de atividades, mas o emprego e o faturamento estão relativamente concentrados em poucos setores. A indústria de alimentos e bebidas responde por $28,4 \%$ dos empregos e a de têxtil vestuário 20,9\%. Esses dois setores juntos representam praticamente a metade dos empregos industriais. No que diz respeito ao faturamento, a presença da alimentícia é ainda maior, 53,3\% do total, segundo dados da Sefaz-Go9 . Assim, se por um lado economias urbanas são importantes, como evidenciam o IDInd e o IDS elevados, economias de especialização são também muito significativas nesse polo industrial.

A cidade de Anápolis está classificada como Sub-Centro Regional A na REGIC 2018 (IBGE, 2020). Por seu porte, peso industrial e de centro logístico a cidade poderia ser, em tese, uma Capital Regional ${ }^{10}$, como argumentam Roscoche et al (2017). Contudo, Anápolis é um típico caso de polo afetado por importantes efeitos tanto progressivos quanto regressivos que emanam de Goiânia e Brasília, dois polos

9 Os dados da Sefaz-Go são oriundos do sistema de notas fiscais eletrônicas, de forma que não alcança as micro e pequenas empresas enquadradas no Simples, que não são obrigadas a emitir a nota fiscal. Existe, portanto, uma certa sobrestimação dos dados de setores onde as empresas em geral são maiores, como é o caso da alimentícia.

\footnotetext{
${ }^{10} \mathrm{Na}$ hierarquia urbana proposta pelo IBGE, logo após as Metrópoles, categoria em que se enquadra Goiânia, vêm os Centros Regionais, que podem ser classificados em A, B ou C. Goiás não conta com nenhum Centro Regional, o que revela a fragilidade de sua rede de cidades, uma característica das regiões mais periféricas (ROSCOCHE et al, 2017).
} 
dinâmicos que se encontram muito próximos. Assim, a presença de serviços superiores e de sedes de empresas, que são importantes para definir sua capacidade de gestão e comando na estrutura urbana, é pequena no município. Essas atividades são atraídas pelas capitais próximas. Ainda assim, possui um IDSIC elevado e concentra 19,1\% dos ServCT\&I do estado.

A estrutura industrial de Anápolis é diversificada e pouco concentrada. Os setores com mais peso no faturamento da indústria são: o de alimentos, com 14,2\% do total; seguido do papel e seus produtos, com 9,3\%; e o farmacêutico com 7,8\% (Sefaz-Go). Trata-se de uma indústria de baixa e média baixa intensidade tecnológica, apesar de contar com o setor farmacêutico e com automobilística, setores tradicionalmente classificados como de média alta tecnologia. No caso de Anápolis, contudo, seus limitados requisitos em termos de economias de escala e economias urbanas, só permitiram atrair uma farmacêutica concentrada na fase final de mistura e encapsulamento de farmoquímicos importados e uma planta automobilística incapaz de desenvolver no seu entorno sua rede de fornecedores ${ }^{11}$, ambos com baixíssima atividade inovativa. A baixa territorialização de seu tecido produtivo se manifesta não apenas na indústria do próprio município, mas também em sua incapacidade de interagir com seu entorno e de difundir efeitos dinâmicos sobre esses. Em decorrência disso, nenhum outro município integra esse polo.

Quadro 4 - Classificação dos polos industriais de Goiás por tipo

\begin{tabular}{|c|c|}
\hline Tipo & Polos \\
\hline \multirow{2}{*}{ Industrial Urbano } & Goiânia \\
\cline { 2 - 2 } & Anápolis \\
\hline \multirow{2}{*}{ Agroindustrial } & Rio Verde \\
\hline Base Mineral & Itumbiara \\
\hline Misto & Niquelândia \\
\hline
\end{tabular}

Fonte: Elaboração própria

Já os polos de Rio Verde e Itumbiara classificam-se como polos agroindustriais. Ambas as cidades estão identificadas como Sub-Centro Regional A na REGIC 2018, as únicas a exibir esse nível entre os municípios goianos, além de Anápolis ${ }^{12}(I B G E, 2020)$. São municípios que desempenham papel relevante de centralização em suas respectivas regiões, ainda que com atividades de gestão menos complexas.

Rio Verde possui uma indústria fortemente concentrada na produção de alimentos, especificamente nos setores de processamento de grãos e carnes, que representam, isoladamente, $85,9 \%$ do faturamento da indústria no município. Mais do que isso, esses setores constituem o núcleo de um complexo agroindustrial que

\footnotetext{
${ }^{11}$ Ver ARAUJO et al (2017), trabalho que analisa as especificidades dos APLs automobilísticos de Anápolis e Catalão em relação aos demais casos no Brasil.

12 Dada a fragilidade da rede urbana em Goiás, o estado não possui nenhuma cidade classificada como Capital Regional na REGIC 2007, que se situa logo abaixo da categoria Metrópole, na qual se enquadra Goiânia.
} 
integra a produção agropecuária de grãos, aves e suínos, com a indústria processadora, além de um amplo conjunto de indústrias acessórias e de serviços. Essa característica se expressa em uma elevada territorialidade, com importantes encadeamentos para trás e para frente, não apenas produtivos, mas também tecnológicos.

Os encadeamentos da indústria de Rio Verde com sua base agropecuária se espraiam por uma larga região de influência, envolvendo todo a microrregião sudoeste de Goiás, tendo efeito estimulante também sobre a industrialização dos principais municípios da região. Isso se expressa no maior IT entre os polos analisados, de 0,57. Tanto as exigências da agroindústria com a crescente terceirização na agricultura acarretam crescimento e diversificação dos SICs, resultando em um IDSIC de 0,37 . Verifica-se, igualmente, uma presença significativa e crescente de ServCT\&l, de 6,3, revelando uma atividade inovativa relativamente importante.

Itumbiara também possui um tecido industrial bastante concentrado na agroindústria, com um nível de concentração, entretanto, inferior ao de Rio Verde. O setor de alimentos representa $61,3 \%$ do faturamento da indústria, mas seus segmentos são menos concentrados. Destaca-se o complexo agroindustrial de grãos, com maior presença dos derivados de milho, com a participação significativa também de laticínios, sucroalcooleiro e de processamento de vegetais, esse último segmento mais concentrado no município de Morrinhos,.

Itumbiara sofre efeitos regressivos decorrentes de sua proximidade com o polo de Rio Verde. A concentração e desenvolvimento mais acelerado do complexo de grãos e carnes em Rio Verde limitou o crescimento e integração industrial de Itumbiara, que se ressente também da força de atração de capitais e recursos humanos do polo de Uberlândia $(M G)^{13}$. O município possui um tecido produtivo menos integrado e uma economia de menor dinamismo, que se expressa em indicadores mais baixos de IT, IDSIC e ServCT\&T vis-à-vis Rio Verde (Quadro 3).

O polo de Niquelândia classifica-se como de base mineral. Em Niquelândia e na vizinha Barro Alto situa-se a maior reserva de níquel do Brasil e uma das maiores do mundo, exploradas pelos grupos Anglo American e a Votorantim Metais. É um segmento, entretanto, cujas atividades a montante, com exceção do próprio minério, localizam-se integralmente fora da região, como revela seu baixíssimo IT de 0,13 . O mesmo acontece com seus encadeamentos a jusante. Sua produção se destina principalmente à de aço inoxidável no centro sul e, sobretudo, fora do país. A economia de Niquelândia é desconectada, inclusive, da dos demais municípios de base mineral da região, que sediam igualmente grandes operações realizadas por multinacionais do setor, como de exploração de amianto em Minaçu, e de ouro em Crixás, Alto Horizonte e Pilar de Goiás. Trata-se de atividades totalmente desconectadas entre si e com a economia local e regional, o que se traduz em baixíssimos índices IDInd, IDS, IDSIC e de ServCT\&I (Quadro 3). Traduz-se, ainda, em uma frágil rede urbana regional. Niquelândia se classifica como Centro de Zona B na REGIC, o que significa que exerce apenas uma centralidade restrita sua área imediata, com funções de gestão elementares. Na microrregião onde se situa o

\footnotetext{
${ }^{13}$ Importante centro econômico e logístico do Triângulo Mineiro situado a 140 km de Itumbiara.
} 
polo, a de Porangatu, não existe nenhuma cidade que ocupe estratos superiores a esse na REGIC, isto é, que exerça um papel mais amplo de gestão e comando do território ${ }^{14}(I B G E, 2020)$.

Por fim há o polo de Catalão, classificado como misto. Estrategicamente situado na fronteira com Minas Gerais e na linha da estrada de ferro que liga Goiás aos portos de Santos e Vitória, o município de Catalão foi um dos primeiros do estado a se industrializar, ainda no início do século XX. Foi somente em meados dos anos 1970, entretanto, com a implantação do complexo minero-químico de exploração de rochas fosfáticas e produção de fertilizantes, que a indústria passou a ocupar um papel mais importante.

Catalão, contudo, deixou de ser apenas um polo mineral no final dos anos 1990, quando se implantou no município uma unidade da Mitsubishi Motors do Brasil. Apesar de não possuir uma rede muito importante de fornecedores locais ${ }^{15}$, a presença da montadora contribuiu para ampliar a diversificação industrial e do setor de serviços em Catalão. Além disso, o município possui também uma produção agropecuária não desprezível, com algum desdobramento agroindustrial. Em razão de tudo isso seus indicadores se aproximam muito mais dos de Itumbiara, um polo agroindustrial, do que de Niquelândia, um típico polo mineral (Quadro 3). Todavia, seu papel na rede urbana regional (Centro de Zona A) é inferior ao de Itumbiara (Centro Sub-Regional A), bem como sua capacidade de impactar a economia da sua região. Isso se explica, em parte, em razão de que os encadeamentos produtivos da indústria catalana com os municípios do seu entorno são mais limitados do que os que Itumbiara possui com sua própria área de influência.

\section{Considerações Finais}

Ao analisar os caminhos seguidos pela industrialização em diferentes regiões de um estado periférico como Goiás, o artigo destacou a importância de se compreender o desenvolvimento não com um processo padronizado e linear, mas como um processo complexo e diversificado, no qual a história e o espaço importam. A tipologia proposta, classificando os polos industriais em urbanos, agroindustriais, de base mineral e mistos, permitiu destacar as especificidades das trajetórias, estruturas e dinâmicas de cada um deles.

Considerando-se o desenvolvimento industrial do estado como um todo, trata-se de trajetórias complementares. Aliadas aos incentivos fiscais, as economias urbanas do eixo Goiânia-Anápolis possibilitaram uma maior diversificação da indústria no estado, com a emergência de segmentos como o automobilístico e o químico-farmacêutico, nos quais Goiás não possui vantagens comparativas naturais. Contudo, permanece como um desafio para a política industrial estadual criar condições para que essas atividades ampliem sua capacidade de inovar e agregar valor localmente.

\footnotetext{
${ }^{14}$ Existem mais duas classificadas como Centro de Zona B, Porangatu e Uruaçu, e todas as demais são apenas Centros Locais, i.e., possuem centralidade somente em relação à sua própria população rural (IBGE, 2020)

${ }^{15}$ Para saber mais ver ARAUJO et al (2017).
} 
No caso dos polos minerais do norte do estado, apesar de mobilizarem elevados investimentos os mesmos permanecem como enclaves, com baixa capacidade de dinamização da economia da região. As possibilidades de maior verticalização dessas atividades no próprio estado parecem muito improváveis. Estratégias de explorar melhor a oferta local de serviços, e a busca criativa e inovadora de novos nichos de mercado para produtos e/ou subprodutos do potencial mineral local, podem ser examinadas.

No que se refere aos polos agroindustriais, a integração entre indústria e agropecuária de base local e, crescentemente, de serviços intensivos em conhecimento, cria uma dinâmica regional virtuosa propagando efeitos de crescimento e transformação no interior do estado. Ao mesmo tempo, devido a sua escala, suas atividades têm impacto expressivo na economia estadual e nacional.

No entanto, seu foco na produção de commodities, tanto agrícolas como industriais, torna esses polos vulneráveis às oscilações de preços típicas desse tipo de produto, além de implicar em baixa capacidade de agregação de valor dessas economias.

Contudo, os avanços na biotecnologia e na chamada química verde, aliados à crescente demanda por sustentabilidade, têm permitido o surgimento de uma ampla gama de novos produtos derivados de biomassa de origem agropecuária. Assim, com políticas adequadas, é possível se avançar no desenvolvimento de segmentos mais intensivos em conhecimento e valor nesses polos, a partir da moderna base agroindustrial existente.

Enfim, os resultados do artigo trazem indicações importantes para a formulação de políticas industriais subnacionais, sublinhando a necessidade das mesmas respeitarem as especificidades locais. Sem perder de vista, entretanto, que políticas específicas dessa natureza só fazem sentido na medida em que componham estratégias mais gerais, integradas nas diferentes escalas.

\section{REFERÊNCIAS}

ARBACHE, J. Por que serviçOs? In: BARBOSA et al. (Org) Indústria e desenvolvimento produtivo no Brasil. Rio de Janeiro: Elsevier/FGV, 2015. p. 565-586

ARAUJO, V.M.; BOTELHO, M.R.A; CASTRO, S.D. Efeitos da relocalização da indústria automobilística no Brasil e a formação de arranjos produtivos em regiões periféricas: o caso dos arranjos de Catalão e Anápolis no estado de Goiás. In: OLIVEIRA, C. W. et al (Org). Arranjos produtivos locais e desenvolvimento. Rio de Janeiro: Ipea, 2017. p.137-164.

BRANDÃO, Carlos. The multi-scalar articulation of economic development In: FERNANDEZ, V. R. Development in Latin America: critical Discussions from the Periphery. New York: Palgrave/Macmillan, 2018.

BRASIL. Projeto do II Plano Nacional de Desenvolvimento PND (1974-979). Brasília, 1974. Disponível em < http://www.biblioteca.presidencia.gov.br/publicacoesoficiais/catalogo/geisel/projeto-ii-pnd- 
75_79/@@download/file/Projeto\%20II\%20PND\%2075_79.pdf >. Acesso em 14/04/2019.

BRENNER, T.; CAPASSO, M; DUSCHL M.; FRENKEN, K; TREIBICH, T. Causal relations between knowledge-intensive business services and regional employment growth. Regional Studies, 52 (2), p.172-183, 2018.

CANO, Wilson. Raízes da Concentração Industrial em São Paulo. 322 f. Tese Instituto de filosofia e ciências humanas. Universidade Estadual de Campinas, 1975.

CASSIOLATO, J. E. et al. RedeSist 20 anos: cooperando, criando conceitos, influenciando políticas e acumulando aprendizados. In: Matos, M. et al. (Eds.) APLs: Referencial, experiências e políticas em 20 anos da RedeSist... Rio de Janeiro: Epapers, 2017. p.15-30

CASTRO, S.D. et al. Aprendizados com políticas para APLs e sua conexão com as políticas de desenvolvimento regional, produtivo e inovativo. In: Matos, M. et al. (Eds.) APLs: Referencial, experiências e políticas em 20 anos da RedeSist... Rio de Janeiro: E-papers, 2017. p. 391-468.

CASTRO, S. D. e ARRIEL, M. F. A Indústria no Brasil Central: Transformações, desafios e oportunidades. Conjuntura Econômica Goiana, Goiânia, n. 36, p.21-40, jul. 2016. Disponível: http://www.imb.go.gov.br/pub/conj/conj36/artigo_02.pdf. Acesso em: 19/05/2016.

CASTRO, S. D. Política regional e desenvolvimento: caminhos para o Brasil e para o Nordeste. In: GUIMARÃES, P. F.; AGUIAR, R. A.; LASTRES, H. M. M.; SILVA, M. M. (Orgs). Um olhar territorial para o desenvolvimento: Nordeste. Rio de Janeiro: BNDES, 2014. p.503-539. Disponível em:

https://web.bndes.gov.br/bib/jspui/handle/1408/2801. Acesso em: 15 de outubro de 2017.

CONAB. Companhia Nacional de Abastecimento. Portal de Informações Agropecuárias. Disponível em $<$ https://portaldeinformacoes.conab.gov.br/index.php/safra-serie-historicadashboard> . Acesso em 20/03/2019.

DINIZ, C.C, Desenvolvimento poligonal no Brasil: nem desconcentração, nem contínua polarização. Nova Economia, Belo Horizonte, v. 31, set. 1993. n. 1, p. 35-64. HERNÁNDEZ, R., HUALDE, A., MULDER, N. y SAUVÉ, P. Introduction, en R. Hernández, A. Hualde, N. Mulder y P. Sauvé (eds.): Innovation and internationalization of Latin American services, Santiago de Chile, CEPAL, Naciones Unidas, 2016. p.9-36.

HIRSCHMAN, A.O. Desenvolvimento por efeitos em cadeia: uma abordagem generalizada. In: SORJ, B., CARDOSO, FH., and FONT, M., orgs. Economia e 
movimentos sociais na América Latina. Rio de Janeiro: Centro Edelstein de Pesquisa Social, 2008. p. 21-64.

IBGE. Instituto Brasileiro de Geografia e Estatística. Região de influência das cidades 2018. Rio de Janeiro: IBGE, 2020.

IBGE. Instituto Brasileiro de Geografia e Estatística. Tipologia intraurbana : espaços de diferenciação socioeconômica nas concentrações urbanas do Brasil, IBGE: Rio de Janeiro, 2017. Disponível em $<$ https://biblioteca.ibge.gov.br/visualizacao/livros/liv101470.pdf $>$. Acesso em 12/09/2020.

JACOBS, J. The Economy of Cities. Nova York: Vintage. 1969.

LASTRES, M.M. H.; CASSIOLATO, J.E. APLs, conhecimento, desenvolvimento e os desafios da colonialidade do saber. . In: Matos, M. et al. (Eds.) APLs: Referencial, experiências e políticas em 20 anos da RedeSist... Rio de Janeiro: E-papers, 2017.p. 319-348.

LUNDVALL, B-Å (Ed.). National innovation systems: towards a theory of innovation and interactive learning. London: Pinter, 1992.

MARSHALL, Alfred. Princípios de economia. São Paulo: Ed. Nova Cultural, 1985.

MACEDO, F.C.M.; PORTO, L. R. Proposta de atualização das tipologias da PNDR: nota metodológica e mapas de referência. Instituto de Pesquisa Econômica Aplicada. Brasília: Rio de Janeiro : Ipea, 2018.

MONTEIRO, E. Z., PINA, S. A. M. G., Freire, R. A., \& TURCZYN, D. T. O estudo da morfologia urbana na Região Metropolitana de Campinas. urbe. Revista Brasileira de Gestão Urbana, 12, e20190260, 2020.

MYRDAL, G. Teoria econômica e regiões subdesenvolvidas. 2. ed. Rio de Janeiro: Editora Saga, 1968.

PACHECO, C.A. Desconcentração econômica e fragmentação da economia nacional. Economia e Sociedade, Campinas, n.6, p.113-140, jun. 1996.

SAXENIAN, A. Regional advantage: culture and competition in Silicon Valley and Route 128. Cambridge, Mass: Harvard University Press, xi, 1994, 226 p.

SOBREIRA, D.; PADRÃO,D.L.C. Serviços intensivos em conhecimento e serviços tradicionais: um panorama intersetorial de micro e pequenas empresas. REGEPE, São Paulo, v.8, n.3, p.166-199, set/dez. 2019.

STADUTO, Jefferson Andronio Ramundo; PINELA, Sandra Regina da Silva; WILLERS, Ednilse Maria. Tipologia de cluster no abate e preparo da carne de frango: um 
estudo no Estado do Paraná. Redes (St. Cruz Sul, Online), Santa Cruz do Sul, v. 23, n. 2, p. 264-289, maio 2018. ISSN 1982-6745. doi:

https://doi.org/10.17058/redes.v23i2.9836

WEBER, A. Theory of the Location of Industries. Chicago: The University of Chicago Press, 1929. Disponível em <www.economia.unam.mx/cedrus/descargas/Libro\%20de\%20Weber.pdf > . Acesso em 03/03/2019.

Sergio Duarte de Castro. Professor titular da Pontificia Universidade Católica de Goiás (PUCGo) no Programa de Mestrado em Desenvolvimento e Planejamento Territorial. E-mail sergioucg@gmail.com

Daniel Diniz Dias Batista. Titulação. Mestrando em Desenvolvimento e Planejamento Territorial. E-mail dinizdiasbatistadaniel@gmail.com

Como citar: CASTRO, Sergio Duarte de; BATISTA, Daniel Diniz Dias. Desconcentração polarizada da indústria em Goiás. Redes (St. Cruz Sul, Online), Santa Cruz do Sul, v. 25, p. 2203-2226, 2020. ISSN 1982-6745. doi:https://doi.org/10.17058/redes.v25io.13583.

\section{CONTRIBUIÇÃO DE CADA AUTOR}

a. Fundamentação teórico-conceitual e problematização: Sergio Duarte de Castro b. Pesquisa de dados e análise estatística: Sergio Duarte de Castro e Daniel Diniz Dias Batista

c. Elaboração de figuras e tabelas: Sergio Duarte de Castro e Daniel Diniz Dias Batista

d. Fotos: não se aplica

e. Elaboração e redação do texto: Sergio Duarte de Castro

f. Seleção das referências bibliográficas: Sergio Duarte de Castro

Fontes de financiamento: não se aplica. 